\title{
PENGEMBANGAN FORMULASI CAT TEMBOK EMULSI BERBAHAN ACRYLIC UNTUK MENINGKATKAN DAYA SAING IKM
}

\section{DEVELOPMENT OF ACRYLIC EMULSION WALL PAINT FORMULATION FOR IMPROVING SME'S COMPETITIVENESS}

\author{
Deni Cahyadi, Daniel Fajar Puspita \\ Balai Besar Bahan dan Barang Teknik, Jl. Sangkuriang No.14, Bandung 40135 \\ Email: ajeungan@gmail.com
}

Diterima: 17 April 2014

Direvisi: 20 Mei 2014

Disetujui: 20 Juni 2014

\begin{abstract}
ABSTRAK
Penelitian mengenai formulasi cat tembok emulsi berbahan acrylic telah dilakukan. Penelitian ini bertujuan agar cat tembok yang dihasilkan dapat memenuhi 2 (dua) kriteria, yaitu memenuhi Standar Nasional Indonesia dan dapat diterapkan pada industri rumahan atau Industri Kecil Menengah (IKM). Pada penelitian ini cat tembok yang dihasilkan merupakan cat berbasis air dengan menggunakan bahan pengikat jenis acrylic dan bahan baku lain seperti titanium dioksida, kalsium karbonat, kaolin, tipol, ethylene glycol, ecocide, nofoam, texanol dan disloid. Pembuatan cat dilakukan dengan mencampurkan bahan baku dengan jumlah dan urutan tertentu sambil diaduk dengan waktu tertentu. Cat yang dihasilkan diuji terhadap parameter uji sesuai dengan persyaratan mutu pada SNI 3564:2009, "Cat Tembok Emulsi”. Berdasarkan hasil pengujian, cat tembok yang dihasilkan memiliki daya tutup (Pfund) $10 \mathrm{~m}^{2} / \mathrm{L}$, berat jenis 1,48 g/mL, kehalusan 38 micron, kering sentuh 6 menit, kering keras 10 menit, padatan total 57,1 \%berat, $\mathrm{pH}$ 8,13, kekentalan $106 \mathrm{KU}$, lolos uji ketahanan cuaca dan tidak mengandung logam berat. Dari hasil yang diperoleh dapat disimpulkan bahwa cat yang dihasilkan memenuhi persyaratan SNI 3564:2009.
\end{abstract}

Kata kunci: cat tembok, acrylic, logam berbahaya, IKM

\begin{abstract}
Research on acrylic emulsion wall paint formulation has been done. This research was aimed to produce wall paint with 2 (two) criteria, that are complying Indonesian National Standard (SNI) and can be applied at home industry or Small Medium Enterprises (SME). The wall paint is water-based paint and produced with acrylic as the binder and other raw materials such as titanium dioxide, calcium carbonate, kaolin, tipol, ethylene glycol, ecocide, nofoam, texanol and disloid. Paint was made by mixing certain amount of raw materials in a certain sequence, and stirred with certain duration. Paint was tested according to SNI 3564:2009,"Cat Tembok Emulsi". According to test result, wall paint produced has covering degree (Pfund) $10 \mathrm{~m}^{2} / \mathrm{L}$, density $1.48 \mathrm{~g} / \mathrm{mL}$, fineness 38 micron, touch dryness 6 minutes, hard dryness 10 minutes, total solid $57.1 \%$ weight, $p H$ 8.13, viscosity $106 \mathrm{KU}$, pass the weather resistance test and does not contain heavy metals ion. Based on the result obtained, it can be concluded that the wall paint produced comply to SNI product specification.
\end{abstract}

Keywords: wall paint, acrylic, hazardous metals, home industry

\section{PENDAHULUAN}

Pembuatan cat merupakan suatu pekerjaan desain tentang teknik pencampuran bahan baku sedemikian rupa sehingga menghasilkan cat dengan kualitas yang sesuai persyaratan dan warna yang diharapkan. Pekerjaan riset bahan baku, pengembangan teknik pencampuran dan penentuan formulasi, tentu memerlukan investasi yang tidak sedikit. Bagi industri besar dan menengah dengan modal yang cukup hal ini dapat dilakukan, karena merupakan suatu kewajiban industri untuk menjaga kualitas dan menghasilkan produk cat yang inovatif.

Industri cat di Indonesia terus mengalami peningkatan setiap tahunnya, menurut hasil survey dari PT. Mars Indonesia [1], pada tahun 2012 yang lalu pertumbuhan industri cat nasional diperkirakan tidak kurang dari 10\% per tahun, dengan nilai pasar cat di Indonesia mencapai Rp 
10,47 triliun pada tahun 2010, kemudian pada tahun 2011 meningkat sekitar 8,6\% atau sekitar Rp 11,37 triliun dan pada tahun 2012 diperkirakan nilai pasar cat ini tidak kurang dari Rp 12,57 triliun atau naik 10\%. Dari sisi volume pasar, pada 2010 yang lalu total cat bermerek dalam negeri mencapai 688.770 ton, dimana pada 2011 meningkat menjadi 748.004 ton. Pada tahun 2012 mencapai 822.804 ton. Peningkatan konsumsi cat nasional sangat dipengaruhi oleh perkembangan sektor properti dan perumahan, sehingga diperkirakan tingkat konsumsi cat akan didominasi oleh cat dekoratif, termasuk kepada jenis cat ini adalah cat tembok dan cat kayu/ besi baik water-based maupun solvent-based [1].

Cat tembok untuk keperluan dekoratif dapat dihasilkan dengan menggunakan teknologi yang sederhana dan investasi yang murah. Peralatan utama yang digunakan untuk menghasilkan cat tembok adalah pengaduk (mixer) yang nilai investasinya dapat disesuaikan dengan kecukupan modal dan kapasitas produksi.

Industri Kecil Menengah (IKM) yang menghasilkan produk cat atau biasa dikenal dengan istilah cat rumahan atau "cat kiloan" berkembang pesat didorong oleh perkembangan sektor properti pada segmen masyarakat menengah ke bawah. Toko-toko yang menjual cat kiloan dapat dengan mudah ditemukan baik di daerah perkotaan maupun di daerah seperti di kota Bandung, Bogor, Bekasi, dan Kabupaten Bandung.

Dampak negatif yang mungkin timbul akibat dari menjamurnya industri cat kiloan dengan harga murah adalah munculnya produk cat dengan kualitas yang beragam. Standar Nasional Indonesia (SNI), untuk produk cat tembok, SNI 2564:2009 "Cat Tembok Emulsi", dapat dijadikan acuan untuk melindungi kepentingan konsumen dan sebagai barrier bagi produk impor untuk melindungi industri dalam negeri [2].

Kebijakan industri nasional tentang industri hijau atau industri ramah lingkungan merupakan salah satu usaha pemerintah untuk menjaga kelestarian lingkungan dan kesehatan masyarakat. Seluruh sektor industri, termasuk industri cat didorong untuk melakukan inovasi dan menghasilkan produk yang lebih ramah lingkungan. Parameter yang penting untuk menjadikan cat ramah lingkungan adalah digunakannya cat yang berbasis air (waterbased/ waterborne - low VOC) dan bahan yang tidak mengandung logam berat terutama timbal (leadfree).

Cat merupakan campuran dari bahan pengikat, bahan pengisi, pelarut dan sejumlah kecil aditif. Salah satu bahan pengikat atau binder berbasis air yang tidak mengandung logam berat terutama timbal adalah jenis acrylic [3].

Investasi untuk riset dalam rangka mengembangkan kualitas produk merupakan hal yang sulit dilakukan oleh IKM, terutama diakibatkan oleh keterbatasan modal dan sumber daya manusia. Dukungan pemerintah dalam bentuk bantuan pengembangan teknologi untuk meningkatkan kualitas produk tentu akan sangat membantu industri rumahan dan IKM untuk dapat terus mengembangkan usahanya dan meningkatkan kesiapan untuk mendukung kebijakan pemerintah dalam melindungi konsumen dan industri dalam negeri melalui kebijakan pemberlakuan SNI wajib.

Penelitian ini dilakukan untuk membuat cat yang ramah lingkungan dengan menggunakan metode dan teknik pembuatan yang sederhana, peralatan yang murah dan bahan baku yang mudah diperoleh di toko kimia, sehingga diharapkan dengan mudah dapat langsung diterapkan di industri rumahan atau IKM.

\section{BAHAN DAN METODE}

Penelitian ini dilakukan di Laboratorium Balai Besar Bahan dan Barang Teknik. Bahan yang digunakan dalam penelitian, yaitu bahan pengikat (binder) menggunakan material berbasis polimer styrene-acrylic (acronal), pewarna (pigment) untuk warna putih menggunakan material titanium dioksida $\left(\mathrm{TiO}_{2}\right)$, bahan pengisi (filler) menggunakan material kapur $\left(\mathrm{CaCO}_{3}\right)$ dan kaolin, pengental menggunakan natrosol, pengatur $\mathrm{pH}$ menggunakan larutan $\mathrm{NaOH}$, dispersing agent menggunakan disloid, wetting agent menggunakan tipol, anti busa menggunakan nofoam, coalesting agent menggunakan texanol, co-solvent menggunakan ethylene glycol, preservatif menggunakan ecocide, dan untuk pelarut digunakan air keran.

Tahap awal penelitian adalah melakukan pemilihan bahan baku yang ramah lingkungan dan memastikan ketersediaan bahan baku di toko-toko kimia atau pabrik di wilayah Bandung dan sekitarnya untuk memastikan ketersediaan dan kemudahan untuk memperoleh bahan baku 
pembuatan cat.

Selanjutnya membuat desain formulasi dan pengujian supaya dapat menghasilkan cat tembok dengan kualitas yang memenuhi persyaratan SNI 3564:2009. Formulasi yang dihasilkan diharapkan dapat memenuhi persyaratan SNI dan harga produk dapat terjangkau. Langkah yang dilakukan adalah dengan membuat kombinasi komposisi kandungan titanium dioksida dan kalsium karbonat sebagai substitusinya [4].

Cat dibuat dengan langkah-langkah sebagai berikut:

1. Masukkan air kedalam wadah proses dan pastikan mixer terendam sempurna (tidak terjadi cipratan yang berlebih saat mesin dinyalakan)

2. Nyalakan mixer dan masukkan pengental serbuk (natrosol) sedikit demi sedikit sambil terus diaduk; tambahkan larutan $\mathrm{NaOH}(p H$ adjuster) sambil terus diaduk; lakukan pengadukan selama 3-5 menit hingga larutan mengembang

3. Masukkan dispersing agent (disloid) sambil terus diaduk; tambahkan wetting agent (tipol) sambil terus diaduk; kemudian masukkan defoamer (nofoam) sambil terus diaduk; pengadukan tetap dilakukan selama 2-3 menit;

4. Masukkan $\mathrm{TiO}_{2}$ sedikit demi sedikit sambil terus diaduk; tambahkan kaolin sambil terus diaduk; kemudian masukkan filler $\left(\mathrm{CaCO}_{3}\right)$ sedikit demi sedikit sambil terus diaduk;
5. Bersihkan dinding tangki dari pigment dan filler yang menempel menggunakan scraper, kemudian emulsi diaduk hingga mencapai kehalusan yang diinginkan ( \pm 15 menit); Setelah fineness tercapai,

6. Masukkan binder sambil diaduk; kemudian tambahkan preservative, defoamer (nofoam), Coalescing Agent (Texanol), Co-Solvent (Ethylene Glycol) berturut-turut sambil terus diaduk; hingga homogen selama \pm 5 menit, kemudian ambil contoh cat untuk diuji kualitasnya.

Pengujian terhadap produk cat dilakukan sesuai dengan parameter pengujian pada SNI 3564:2009, termasuk parameter logam berbahaya.

\section{HASIL DAN PEMBAHASAN}

Untuk menghasilkan cat tembok yang diharapkan, pada penelitian ini dibuat sejumlah kombinasi formulasi dari bahan baku cat yang akan digunakan. Komponen yang akan divariasikan adalah titanium dioksida dan kalsium karbonat. Titanium dioksida merupakan komponen yang sangat penting dan penyumbang biaya keseluruhan dibandingkan komponen yang lain, dengan demikian penggunaan titanium dioksida yang optimal akan menekan harga bahan baku. Uraian formulasi yang digunakan ditunjukkan pada Tabel 1 [5].

Tabel 1. Formulasi Cat

\begin{tabular}{clccr}
\hline \multirow{2}{*}{ No. } & \multirow{2}{*}{ Bahan Baku } & \multirow{2}{*}{ Rentang Formula } & \multicolumn{2}{c}{ Sampel (F - 6) } \\
& & & \multicolumn{1}{c}{ Berat (g) } \\
\hline 1 & Air & $35,00 \%$ & $35,00 \%$ & 350,00 \\
2 & Pengental Serbuk & $0,50 \%$ & $0,50 \%$ & 5,00 \\
3 & pH Adjuster & $0,01 \%$ & $0,01 \%$ & 0,10 \\
4 & Dispersing Agent & $1,00 \%$ & $1,00 \%$ & 10,00 \\
5 & Wetting Agent & $0,25 \%$ & $0,25 \%$ & 2,50 \\
6 & Defoamer & $4,00 \%$ & $4,00 \%$ & 40,00 \\
7 & $\mathrm{TiO}_{2}$ & $(3-8) \%$ & $4,00 \%$ & 40,00 \\
8 & $\mathrm{Kaolin}_{9}$ & $2,00 \%$ & $2,00 \%$ & 20,00 \\
10 & CaCO $_{3}$ & $(43-49) \%$ & $43,99 \%$ & 439,90 \\
11 & Prinder & $8,00 \%$ & $8,00 \%$ & 80,00 \\
12 & Coalescing Agent & $0,25 \%$ & $0,25 \%$ & 2,50 \\
13 & Co-Solvent & $0,50 \%$ & $0,50 \%$ & 5,00 \\
\end{tabular}

Tabel 2. Hasil Pengujian Cat 


\begin{tabular}{clcccc}
\hline No. & Parameter Uji & Satuan & $\begin{array}{c}\text { Persyaratan SNI } \\
\mathbf{3 5 6 4 : 2 0 0 9}\end{array}$ & Rentang Hasil Uji & Sampel (F - 6) \\
\hline 1 & Daya Tutup (Pfund) & $\mathrm{m}^{2} / \mathrm{L}$ & min. 8 & $7-25$ & 10 \\
2 & Berat Jenis & $\mathrm{g} / \mathrm{mL}$ & min. 1,2 & $1,2-1,5$ & 1,48 \\
3 & Kehalusan & micron & maks. 50 & 38 & 38 \\
4 & Kering Sentuh & menit & maks. 30 & $6-10$ & 6 \\
5 & Kering Keras & menit & maks. 60 & $10-25$ & 10 \\
6 & Padatan Total & \% berat & min. 40 & $55-64$ & 57,1 \\
7 & pH & - & $7-9,5$ & $7-8$ & 8,13 \\
8 & Kekentalan & $K U$ & min. 90 & $106-124$ & 106 \\
\hline
\end{tabular}

Cat yang dihasilkan kemudian diuji kualitasnya yang meliputi parameter daya tutup, berat jenis, kehalusan, kering sentuh, kering keras, padatan total, $\mathrm{pH}$ dan kekentalan sesuai dengan cara uji menurut SNI dan ASTM [2, 6, 7, 8, 9, 10]. Hasil analisa cat dapat dilihat pada Tabel 2.

Pengujian ketahanan cuaca dipercepat, dilakukan terhadap salah satu produk yang dihasilkan, dengan menggunakan alat Q-UV accelerated weathering test (persyaratan khusus SNI 3564:2009), pada kondisi lampu: UV-B 313 EL $\lambda$ : $310 \mathrm{~nm}$; UV selama 4 jam pada temperatur $60^{\circ} \mathrm{C}$; kondensasi selama 4 jam pada temperatur $50^{\circ} \mathrm{C}$.

Untuk mengetahui kandungan logam berbahaya pada produk cat, dilakukan pengujian kandungan logam yaitu $\mathrm{Pb}, \mathrm{Cd}, \mathrm{Hg}$ dan $\mathrm{Cr}$ (VI). Logam $\mathrm{Pb}$ dan $\mathrm{Cd}$, menggunakan metode uji $\mathrm{AAS}$
(Atomic Absorption Spectrophotometry), metode uji spektrofotometer untuk kromium heksavalen dan logam Hg menggunakan HVGAAS.

Pengujian cat dilakukan di laboratorium Balai Besar Kimia Kemasan, Jakarta. Hasil uji dapat dilihat pada Tabel 4. Hasil uji yang terdapat pada Tabel 4 merupakan batasan kemampuan deteksi alat. Dari hasil pengujian cat tembok tersebut tidak terdeteksi adanya logam berat (timbal, cadmium, kromium heksavalen dan raksa).

Berdasarkan hasil pengujian yang dilakukan terhadap salah satu contoh cat yang dihasilkan dengan kode formulasi F-6, memenuhi persyaratan mutu SNI. Baik persyaratan umum pada Tabel 2 maupun persyaratan khusus pada Tabel 3.

Tabel 3. Hasil Uji Ketahanan Cuaca Dipercepat

\begin{tabular}{lll}
\hline Uraian Pengujian & $\begin{array}{l}\text { Hasil Uji } \\
\text { Kode Formula F6 }\end{array}$ & Persyaratan SNI 3564:2009 \\
\hline Penilaian: & & \\
\hline 1.Perubahan warna, visual & Tidak ada & Tidak ada perubahan \\
\hline $\begin{array}{l}\text { 2.Perubahan warna dengan } \\
\text { skala Grey scale }\end{array}$ & $\begin{array}{l}\text { Skala 5 } \\
\text { (no deterioration) }\end{array}$ & Tidak ada perubahan \\
\hline 3.Perubahan lain & Tidak ada & Tidak ada perubahan \\
\hline * Ketahanan terhadap cuaca dipercepat dengan alat Q-UV accelerated weathering tester, selama 600 jam
\end{tabular}


Tabel 4. Hasil Uji Logam Berbahaya

\begin{tabular}{llll}
\hline Uraian Pengujian & $\begin{array}{l}\text { Hasil Uji } \\
\text { Contoh F6 }\end{array}$ & Metode & $\begin{array}{l}\text { Persyaratan SNI } \\
\mathbf{3 5 6 4 : 2 0 0 9}\end{array}$ \\
\hline $\begin{array}{l}\text { Kandungan logam berat, dalam } \\
\text { satuan ppm }\end{array}$ & & & \\
Logam: & $<1,4 \mathrm{ppm}$ & AAS & Tidak terdeteksi \\
a) Timbal, Pb & $<0,4 \mathrm{ppm}$ & AAS & Tidak terdeteksi \\
b) Kadmium, Cd & $<0,17 \mathrm{ppm}$ & Spektrofotometer & Tidak terdeteksi \\
c) Kromium heksavalen, Cr (VI) & $<0,045 \mathrm{ppm}$ & HVG-AAS & Tidak terdeteksi \\
d) Raksa, Hg & & & \\
\hline
\end{tabular}

Tinjauan sederhana dari aspek kelayakan ekonomi dilakukan dengan melakukan perhitungan terhadap biaya bahan baku yang diperlukan. Upaya estimasi biaya atau harga cat yang dihasilkan dihitung berdasarkan parameter bahan baku. Untuk keperluan air, diperkirakan harga air PDAM Rp. $3000 / \mathrm{m}^{3}$, dan persentase penggunaan air dalam pembuatan $1 \mathrm{~kg}$ cat dikeluarkan untuk penggunaan air PDAM adalah sebesar Rp. 1,05/kg cat tembok. Selanjutnya estimasi biaya produksi untuk bahan baku yang lain dapat dilihat pada Tabel 5.

Jadi total biaya (termasuk air) bahan baku untuk membuat $1 \mathrm{~kg}$ cat tembok adalah sebesar Rp. 6.521,-/kg.

Tabel 5. Estimasi Biaya Bahan Baku

\begin{tabular}{|c|c|c|c|c|c|c|c|}
\hline \multirow{2}{*}{$\begin{array}{c}\text { No } \\
1\end{array}$} & \multirow{2}{*}{$\begin{array}{l}\text { Bahan Baku } \\
\text { Air }\end{array}$} & \multirow{2}{*}{$\begin{array}{c}\text { Kode } \\
\mathrm{X}\end{array}$} & \multicolumn{2}{|c|}{ Harga/kg } & \multicolumn{2}{|c|}{ F - 6} & \multirow{2}{*}{$\begin{array}{c}\begin{array}{r}\text { Presentase } \\
\text { Formulasi }\end{array} \\
35,00 \%\end{array}$} \\
\hline & & & (Rp. 3 & $\left.000 / \mathrm{m}^{3}\right)$ & $\mathrm{Rp}$ & 1 & \\
\hline 2 & Pengental Serbuk & A & $\mathrm{Rp}$ & 98.000 & Rp & 490 & $0,50 \%$ \\
\hline 3 & pH Adjuster & B & Rp & 6.000 & Rp & 1 & $0,01 \%$ \\
\hline 4 & Dispersing Agent & $\mathrm{C}$ & Rp & 16.700 & Rp & 167 & $1,00 \%$ \\
\hline 5 & Wetting Agent & $\mathrm{D}$ & Rp & 6.000 & Rp & 15 & $0,25 \%$ \\
\hline 6 & Defoamer & E & Rp & 17.100 & Rp & 684 & $4,00 \%$ \\
\hline 7 & $\mathrm{TiO}_{2}$ & $\mathrm{~F}$ & $\mathrm{Rp}$ & 48.000 & $\mathrm{Rp}$ & 1.920 & $4,00 \%$ \\
\hline 8 & Kaolin & G & Rp & 7.000 & Rp & 140 & $2,00 \%$ \\
\hline 9 & $\mathrm{CaCO}_{3}$ & $\mathrm{H}$ & Rp & 2.000 & Rp & 880 & $43,99 \%$ \\
\hline 10 & Binder & I & Rp & 21.700 & Rp & 1.736 & $8,00 \%$ \\
\hline 11 & Preservative & $\mathrm{J}$ & Rp & 26.700 & Rp & 67 & $0,25 \%$ \\
\hline 12 & Coalescing Agent & K & Rp & 34.200 & Rp & 171 & $0,50 \%$ \\
\hline 13 & Co-Solvent & $\mathrm{L}$ & $\mathrm{Rp}$ & 50.000 & $\mathrm{Rp}$ & 250 & $0,50 \%$ \\
\hline \multicolumn{5}{|c|}{ TOTAL } & $\mathbf{R p}$ & 6.520 & $100 \%$ \\
\hline
\end{tabular}

\section{KESIMPULAN}

Berdasarkan penelitian yang dilakukan, untuk menghasilkan cat tembok yang ramah lingkungan dan dapat memenuhi persyaratan SNI 3564:2009, dapat digunakan bahan-bahan yang tersedia di pasar lokal dengan formulasi: air (35\%), pengental (0,5\%), $p H$ adjuster $(0,01 \%)$, defoamer $(4 \%), \mathrm{TiO}_{2}(4 \%)$, kaolin (2\%), $\mathrm{CaCO}_{3}(43,99 \%)$, binder acrylic (8\%), preservatif $(0,25 \%)$, coalescing agent $(0,5 \%)$, dan co-solvent $(0,5 \%)$. Cat dapat dihasilkan dengan menggunakan teknik produksi dan peralatan yang sederhana, sehingga berpotensi untuk dapat diterapkan di industri rumah tangga atau IKM.

\section{UCAPAN TERIMA KASIH}

Penulis mengucapkan terima kasih kepada Kepala Balai Besar Bahan dan Barang Teknik, Saudara Jajuli, Indra, Momon, Taufik Prawoto, dan Ade Nurul, yang telah membantu dalam penelitian ini. 


\section{DAFTAR PUSTAKA}

[1] Anonim, 2013, “Tidak Mudah Bermain Bisnis di Cat”, http://newsletter.marsindonesia.com/2013 105/21/tidak-mudah-bermain-di-bisnis-cat, diakses tanggal 21 Mei 2013.

[2] Standar Nasional Indonesia, 2009, "SNI 3564 : Cat Tembok Emulsi”.

[3] Rtopcuoglu, Ozge., Sacide A.A., Devrim B., "Characterization of Waterborne Acrylic Based Paint Films and Measurement of Their Water Vapor Permeabilities", Progress in Organic Coatings 56 296-278, Elsevier, 2006.

[4] Tarng, Ming-Ren Irvine., et. al. (2012), "Exterior Paint Formulation”, European Patent, EP2292702 B1.

[5] Jajuli, dkk. (2013) "Pembuatan Cat Tembok Water Based Acrylic Styrene Ramah Lingkungan”, Laporan Kegiatan, Balai Besar Bahan dan Barang Teknik, Bandung: Tidak diterbitkan.
[6] American Society for Testing and Material, 2003, “ASTM D1475: Standard Test Method for Density of. Paint, Varnish, Lacquer, and Related Products".

[7] American Society for Testing and Material, 2004, “ASTM D1210 : Standard Test Method for Fineness of Dispersion of Pigment".

[8] American Society for Testing and Material, 1999, “ASTM D1640 : Standard Test Methods for Drying, Curing, or Film Formation of Organic Coatings at Room Temperature".

[9] American Society for Testing and Material, 2007, “ASTM D 2369 : Standard Test Method for Volatile Content of Coatings".

[10] American Society for Testing and Material, 2005, “ASTM D 562 : Standard Test Method for Consistency of Paints Measuring Krebs Unit (KU) Viscosity Using a Stormer-Type Viscometer". 